\section{A Retrospective Review of High versus Standard Dose Dexmedetomidine for Sedation in Critically III Patients}

\section{Abstract}

Introduction: Studies have demonstrated safety and efficacy of dexmedetomidine infusions at doses up to $1.5 \mathrm{mcg} / \mathrm{kg} / \mathrm{hr}$. Data evaluating doses greater than $1.5 \mathrm{mcg} / \mathrm{kg} / \mathrm{hr}$ is limited; however, up to $2.5 \mathrm{mcg} / \mathrm{kg} / \mathrm{hr}$ has been utilized. It is uncertain whether higher doses provide additional benefit but may result in more adverse events. The purpose of this study was to compare the safety and efficacy of dexmedetomidine at high doses (greater than $1.5 \mathrm{mcg} / \mathrm{kg} / \mathrm{hr}$ ) versus standard doses $(0.2$ to $1.5 \mathrm{mcg} / \mathrm{kg} / \mathrm{hr}$ ).

Methods: A retrospective cohort study was conducted in critically ill, mechanically ventilated patients receiving dexmedetomidine for at least 24 hours. Standard dose dexmedetomidine (SD-DEX) was defined as less than or equal to $1.5 \mathrm{mcg} / \mathrm{kg} /$ $\mathrm{hr}$ and high dose (HD-DEX) as greater than $1.5 \mathrm{mcg} / \mathrm{kg} / \mathrm{hr}$. Patients were assigned to SD-DEX group if maximum dose of dexmedetomidine received was between 0.2 and $1.5 \mathrm{mcg} / \mathrm{kg} / \mathrm{hr}$. Conversely, patients were assigned to HD-DEX group if maximum dose of dexmedetomidine received was greater than $1.5 \mathrm{mcg} / \mathrm{kg} / \mathrm{hr}$. Composite incidence of bradycardia or hypotension and proportion of time within target sedation were assessed.

Results: A total of 799 patients were screened for inclusion with 120 included: 69 in the HD-DEX group and 51 in the SD-DEX group. Composite incidence of bradycardia or hypotension was not statistically different. A significantly larger proportion of time was spent within target sedation in the SD-DEX group. More patients in the HD-DEX group required sedatives and antipsychotics than the SDDEX group and tended to receive higher daily doses of concomitant medications.

Conclusion: Dexmedetomidine doses greater than $1.5 \mathrm{mcg} / \mathrm{kg} / \mathrm{hr}$ may be as safe as standard doses; however, no additional benefit in maintaining target sedation level was found.

Keywords: Dexmedetomidine; Sedation; Critically ill; High dose; Bradycardia; Hypotension; RASS
Kellie Rodriguez ${ }^{1}$,

Rebecca L Anderson ${ }^{2}$, Georgia Keriazes ${ }^{2}$ and Bruce Meyers ${ }^{3}$
Corresponding authors: Rebecca L Anderson

झ rebecca.anderson@myLRH.org

PharmD, BCPS, Lakeland Regional Health, Department of Pharmacy, 1324 Lakeland Hills Boulevard, Lakeland, FL 33805, USA.

\section{Tel: $8636871100 / 7781$}

Citation: Rodriguez K, Anderson RL, Keriazes G, et al. A Retrospective Review of High versus Standard Dose Dexmedetomidine for Sedation in Critically III Patients. J Intensive \& Crit Care 2016, 2:2.

Received: March 15, 2016; Accepted: April 06, 2016; Published: April 13, 2016

\section{Introduction}

Agitation and anxiety in critically ill patients are associated with adverse clinical outcomes, including increased intensive care unit (ICU) stay, duration of mechanical ventilation, occurrence of nosocomial infections, and incidence of selfextubation [1, 2]. Historically, benzodiazepines have been the most commonly administered sedative agents. However, benzodiazepine usage has declined due to an unfavorable safety profile, including an association with prolonged sedation and increased risk of delirium [3, 4]. The Society of Critical Care Medicine (SCCM) Guidelines for Pain, Agitation, and Delirium in ICU patients recommend analgesia-first sedation followed by non-benzodiazepine sedatives, such as dexmedetomidine or propofol [5].

Dexmedetomidine is a highly selective alpha-2 receptor agonist and possesses approximately eight times the specificity for alpha-2 receptors compared to clonidine [6]. Dexmedetomidine exhibits 
sedative, analgesic, and sympatholytic properties [7]. Unlike other sedative agents, dexmedetomidine has no anticonvulsant effects, produces minimal respiratory depression, and allows for light to moderate sedation where patients are easily arousable $[7,8]$. The most common adverse events associated with dexmedetomidine are hypotension and bradycardia [6]. The current FDA-approved dexmedetomidine dosing for ICU sedation includes an optional loading dose of $1 \mathrm{mcg} / \mathrm{kg}$ followed by a continuous infusion for up to 24 hours of 0.2 to $0.7 \mathrm{mcg} / \mathrm{kg} / \mathrm{hr}$ titrated to achieve the desired level of sedation [6].

Several studies including the MENDS, SEDCOM, and MIDEX/ PRODEX trials, have demonstrated the safety and efficacy of infusions at higher doses up to $1.5 \mathrm{mcg} / \mathrm{kg} / \mathrm{hr}$ [9-11]. Due to the additional data presented by these studies, higher doses and longer durations of therapy compared to those FDA-approved for dexmedetomidine are now used in practice. Data evaluating doses greater than $1.5 \mathrm{mcg} / \mathrm{kg} / \mathrm{hr}$ is limited; however, doses up to $2.5 \mathrm{mcg} / \mathrm{kg} / \mathrm{hr}$ have been utilized [11-14]. It is uncertain whether higher doses provide any additional benefit but may result in more adverse events. The purpose of this study was to compare the safety and efficacy of dexmedetomidine in patients receiving high dose (greater than $1.5 \mathrm{mcg} / \mathrm{kg} / \mathrm{hr}$ ) versus standard dose $(0.2$ to $1.5 \mathrm{mcg} / \mathrm{kg} / \mathrm{hr}$ ) dexmedetomidine.

\section{Methods}

A retrospective, cohort study was conducted at an 851bed tertiary-care medical center with 72 ICU beds. A Cerner Analytics ${ }^{\circledR}$ report was used to identify patients who received dexmedetomidine between January 1, 2013 and May 31, 2014 and were subsequently screened for inclusion. The hospital Institutional Review Board approved the protocol and granted a waiver of ethical approval and patient informed consent.

Patients were included if they were at least 18 years of age, admitted or consulted to the Critical Care Medicine service, mechanically ventilated at the time of dexmedetomidine initiation, and received dexmedetomidine for sedation with a target Richmond Agitation Sedation Scale (RASS) of -2 to +1 for at least 24 hours. If patients were admitted for trauma or burns; received neuromuscular blockers, other than for intubation or epidural/spinal analgesia, while receiving dexmedetomidine; received vasopressors throughout the entire study period; were diagnosed with active neurological disease such as severe dementia or active seizures; experienced alcohol withdrawal; were prescribed dexmedetomidine with an indication for sleep; or had a heart rate less than 50 beats/min at initiation of dexmedetomidine they were excluded from evaluation.

Standard dose dexmedetomidine (SD-DEX) was defined as less than or equal to $1.5 \mathrm{mcg} / \mathrm{kg} / \mathrm{hr}$ and high dose dexmedetomidine (HD-DEX) was defined as greater than $1.5 \mathrm{mcg} / \mathrm{kg} / \mathrm{hr}$. Patients were assigned to the SD-DEX group if the maximum dose of dexmedetomidine received at any point was between 0.2 and $1.5 \mathrm{mcg} / \mathrm{kg} / \mathrm{hr}$. Conversely, patients were assigned to the HD-DEX group if the maximum dose of dexmedetomidine received was greater than $1.5 \mathrm{mcg} / \mathrm{kg} / \mathrm{hr}$.

Data collection began at the time of dexmedetomidine initiation for the SD-DEX group, and at the point when a dose greater than 1.5 $\mathrm{mcg} / \mathrm{kg} / \mathrm{hr}$ was reached for the HD-DEX group. Data was collected for both groups until dexmedetomidine was discontinued for at least 48 hours or duration of seven days was reached, whichever occurred first, regardless of dosing modifications. Patient data was only collected for the first course of dexmedetomidine usage and any subsequent usage following a discontinuation of greater than 48 hours was not included in the study. For patients who were administered vasopressors during the study period, data collection was stopped when the vasopressor was initiated.

The primary outcome was a composite of the incidence of bradycardia (heart rate less than 55 beats/min) or hypotension (mean arterial pressure less than $60 \mathrm{mmHg}$ ). The secondary outcome was the proportion of time within target RASS of -2 to +1 , calculated as the time spent within target RASS divided by the total study period of dexmedetomidine. The total study period of dexmedetomidine was defined as the time of study start until time of data collection completion. Other clinical outcomes included use of analgesics, sedatives, and antipsychotics, duration of mechanical ventilation, hospital and ICU LOS, and discharge disposition.

A chi-square analysis was used for all nominal data (i.e. to compare the incidence of adverse events). Continuous data was analyzed using a Mann-Whitney $U$ test (i.e. proportion of time within target RASS). A p-value of less than 0.05 denotes statistical significance.

\section{Results}

A total of 799 patients were screened for inclusion and 120 patients were included in the study: 69 in the HD-DEX group and 51 in the SD-DEX group. The most common reason for study exclusion was not receiving dexmedetomidine for at least 24 hours $(n=253)$, patients not being intubated at time of dexmedetomidine initiation $(n=155)$, and concurrent vasopressor use at the start of dexmedetomidine $(n=56)$.

The groups had similar baseline characteristics (Table 1). All dexmedetomidine dosing parameters were higher in the HDDEX group compared to the SD-DEX group, including an absolute difference in average dose of $1 \mathrm{mcg} / \mathrm{kg} / \mathrm{hr}$ (Table 2). A large proportion of patients in both groups received opioid analgesics; however, more patients in the HD-DEX group required both

Table 1 Baseline characteristics.

\begin{tabular}{|l|c|c|}
\hline Age (years), mean (SD) & $68(11.5)$ & $61(14)$ \\
\hline Gender (male), $\mathrm{n}(\%)$ & $21(42)$ & $34(49)$ \\
\hline Race, $\mathrm{n}(\%)$ & $47(92)$ & $65(94)$ \\
\hline $\begin{array}{l}\text { Caucasian } \\
\text { African-American }\end{array}$ & $4(8)$ & $3(4)$ \\
\hline Hispanic & 0 & $1(2)$ \\
\hline $\begin{array}{l}\text { Past medical history, } \mathrm{n}(\%) \\
\text { Neurologic }\end{array}$ & $9(16)$ & $2(3)$ \\
\hline $\begin{array}{l}\text { Psychiatric } \\
\text { Hepatic }\end{array}$ & $6(12)$ & $10(14)$ \\
\hline Weight (kg), mean (SD) & $5(10)$ & $11(16)$ \\
\hline
\end{tabular}


sedatives and antipsychotics (Table 2). Patients in the HD-DEX group also tended to receive higher daily doses of concomitant medications, including opioids, benzodiazepines, and propofol.

In the primary safety outcome analysis, the composite incidence of bradycardia or hypotension was not statistically different between the groups; however, there were more adverse events in the SD-DEX group (Table 3). Analysis of the secondary efficacy outcome revealed a significantly larger proportion of time within target RASS in the SD-DEX group compared to the HD-DEX group $(p<0.001)$.

Clinical outcomes, including duration of mechanical ventilation and ICU and hospital LOS, were similar between the groups (Table 3). Discharge disposition was not statistically different between the SD-DEX and HD-DEX groups with $33 \%$ versus $46 \%$ of patients being discharge home, respectively.

\section{Discussion}

Several studies have assessed dexmedetomidine usage with doses up to $1.5 \mathrm{mcg} / \mathrm{kg} / \mathrm{hr}$ [9-11]. To our knowledge, no evaluation of dexmedetomidine for sedation in critically ill patients has been performed to determine whether doses greater than $1.5 \mathrm{mcg} /$ $\mathrm{kg} / \mathrm{hr}$ are as safe and effective as those previously studied. Our study suggests that while higher doses of dexmedetomidine may be safe, they may not provide an increased proportion of time within target sedation when compared to standard doses.

All dosing parameters of dexmedetomidine were significantly higher in the HD-DEX group, supporting a meaningful difference in dosing practices between the groups. Since dose titrations are frequently required to maintain desired sedation and avoid adverse events, it was expected that the average HD-DEX dose would be lower than the maximum dose as demonstrated in Table 2. The maximum and average doses of dexmedetomidine in the HD-DEX group ( 2.4 and $1.6 \mathrm{mcg} / \mathrm{kg} / \mathrm{hr}$, respectively) are both greater than $1.5 \mathrm{mcg} / \mathrm{kg} / \mathrm{hr}$ and fall within the prespecified dosing range for the HD-DEX group.

Table 2 Medication administration.

\begin{tabular}{|c|c|c|c|}
\hline & SD-DEX (n=51) & HD-DEX (n=69) & p \\
\hline \multicolumn{4}{|l|}{ Dexmedetomidine } \\
\hline Average dose $(\mathrm{mcg} / \mathrm{kg} / \mathrm{hr})$ & $0.6(0.4-0.8)$ & $1.6(1.2-2.1)$ & $<0.001$ \\
\hline Lowest dose (mcg/kg/hr) & $0.2(0.1-0.3)$ & $0.5(0.3-0.8)$ & $<0.001$ \\
\hline Highest dose (mcg/kg/hr) & $1(0.8-1.4)$ & $2.4(2.1-2.5)$ & $<0.001$ \\
\hline \multicolumn{4}{|l|}{ Concomitant Medications } \\
\hline $\begin{array}{l}\text { Analgesics, } \mathrm{n}(\%) \\
\text { Average daily dose }(\mathrm{mg})^{+}\end{array}$ & $\begin{array}{c}48(94) \\
34(11-67)\end{array}$ & $\begin{array}{c}61(88) \\
51(19-142)\end{array}$ & $\begin{array}{l}0.284 \\
0.085\end{array}$ \\
\hline Sedatives ${ }^{\ddagger}, \mathrm{n}(\%)$ & $34(67)$ & $60(87)$ & 0.008 \\
\hline $\begin{array}{l}\text { Benzodiazepines, } \mathrm{n}(\%) \\
\text { Average daily dose }(\mathrm{mg})^{*}\end{array}$ & $\begin{array}{l}31(61) \\
4(3-11)\end{array}$ & $\begin{array}{l}57(83) \\
9(6-17)\end{array}$ & $\begin{array}{l}0.008 \\
0.028\end{array}$ \\
\hline $\begin{array}{l}\text { Propofol, } \mathrm{n}(\%) \\
\text { Average daily dose }(\mathrm{mg})\end{array}$ & $\begin{array}{c}13(25) \\
170(59-634)\end{array}$ & $\begin{array}{c}16(23) \\
1273(414-2396)\end{array}$ & $\begin{array}{l}0.594 \\
0.024\end{array}$ \\
\hline Antipsychotics, n (\%) & $4(8)$ & $35(51)$ & $<0.001$ \\
\hline
\end{tabular}

median (IQR), unless otherwise specified

†Analgesics reported in morphine equivalents

†Received benzodiazepine(s) and/or propofol

¥Benzodiazepines reported in midazolam equivalents
Table 3 Outcomes.

\begin{tabular}{|c|c|c|c|}
\hline & $\begin{array}{l}\text { SD-DEX } \\
(n=51)\end{array}$ & $\begin{array}{l}\text { HD-DEX } \\
(n=69)\end{array}$ & $\mathbf{p}$ \\
\hline \multicolumn{4}{|l|}{ Outcomes } \\
\hline Composite adverse events ${ }^{\dagger}, \mathrm{n}(\%)$ & $38(75)$ & $41(59)$ & 0.085 \\
\hline Bradycardia, n (\%) & $28(55)$ & $31(45)$ & 0.280 \\
\hline Hypotension, n (\%) & $21(41)$ & $18(26)$ & 0.081 \\
\hline $\begin{array}{l}\text { Proportion of time within target } \\
\text { RASS }\end{array}$ & $97(88-100)$ & $81(70-95)$ & $<0.001$ \\
\hline \multicolumn{4}{|l|}{ Clinical outcomes } \\
\hline $\begin{array}{l}\text { Length of mechanical ventilation } \\
\text { (days) }\end{array}$ & $7.5(4-13)$ & $8(5-15)$ & 0.711 \\
\hline ICU length of stay (days) & $10(7-17.5)$ & $11(6-18)$ & 0.920 \\
\hline Hospital length of stay (days) & $17(12.5-23.5)$ & $17(11-21)$ & 0.897 \\
\hline
\end{tabular}

median (IQR) unless otherwise specified

'Single occurrence of bradycardia or hypotension

Adverse events of dexmedetomidine include hypotension and bradycardia; however, the reported incidence of these events has varied due to differing definitions used in studies [9-11]. Although not statistically significant, patients in the SD-DEX group had a higher rate of hypotension or bradycardia than those in the HD-DEX group. It is possible that a lower heart rate or blood pressure may have limited the ability to titrate dexmedetomidine in the SD-DEX group to doses greater than $1.5 \mathrm{mcg} / \mathrm{kg} / \mathrm{hr}$. Alternatively, patients in the HD-DEX group may have had other factors affecting their hemodynamic state, such as hyperactive delirium, which could have blunted dexmedetomidine's effect in decreasing heart rate or blood pressure. Although delirium was not directly assessed in this study, patients in the HD-DEX group more frequently required antipsychotic medications, suggesting that delirium may have been more common in this group.

Dexmedetomidine provides a light to moderate level of sedation, correlating with a RASS of -2 to +1 [6]. Other sedative medications such as opioids, benzodiazepines, and propofol provide a deeper level of sedation, with the ability to induce RASS scores up to -5 . If a deeper level of sedation than RASS -2 is desired, dexmedetomidine may not be the optimal choice of sedative agent and is unlikely to provide any additional benefit when combined with other sedative medications [15]. This is supported by our results which demonstrate that patients in the HD-DEX group, despite receiving higher doses of dexmedetomidine and other concomitant sedatives, spent less time within target RASS than those in the SD-DEX group. Additionally, a study previously found that doses of dexmedetomidine greater than $0.7 \mathrm{mcg} /$ $\mathrm{kg} / \mathrm{hr}$ did not enhance sedation to target RASS when compared to lower doses, suggesting that even doses up to $1.5 \mathrm{mcg} / \mathrm{kg} /$ $\mathrm{hr}$ may not provide additional benefit [16]. Furthermore, a small prospective study observed variable sedation levels with dexmedetomidine between patients and identified factors that may influence patient response, including lower severity of illness and use of antidepressants at home [17]. These results, combined with those of our study, suggest that not all patients may respond to dexmedetomidine and upward titration of doses may not result in more effective sedation.

Dexmedetomidine is thought to have a beneficial effect on delirium, as demonstrated in previous studies. In the SEDCOM 
trial, the prevalence of delirium was lower in dexmedetomidinetreated patients than those treated with midazolam (54\% vs. $76.6 \%, p<0.001$ ) [8]. Additionally, a small, open-label trial in mechanically ventilated patients with ICU-associated delirium found that dexmedetomidine significantly shortened the duration of propofol requirements, time to extubation, and ICU LOS when compared to haloperidol [18]. These results suggest that dexmedetomidine may have a role in the treatment of ICUassociated delirium. There have been two proposed mechanisms to explain the decrease in delirium with dexmedetomidine [19]. The first theory suggests that dexmedetomidine's lack of action on GABA and acetylcholine receptors as well as its ability to mimic a natural sleep-like state provide for intrinsic delirium-sparing properties. The second theory suggests that dexmedetomidine's ability to decrease the need for GABAminergic agents, such as benzodiazepines, may reduce the risk of developing delirium. Our findings do not support a benzodiazepine-sparing effect as previously described, as a large proportion of patients required concomitant sedative medications, including benzodiazepines and propofol, with a greater requirement observed in the HDDEX group. Additionally, more patients in the HD-DEX group required antipsychotic medications, suggesting that delirium may not have been able to be overcome with administration of dexmedetomidine.

There are some limitations that warrant discussion. The retrospective study design made it difficult to account for all potential confounding variables. Inconsistent documentation methods of medication administration may have allowed for discrepancies in the reported dosing of dexmedetomidine compared to the actual doses administered. Additionally, delirium could not be adequately assessed as there was varying documentation of the Confusion Assessment Method in the ICU (CAM-ICU) assessment scores. Additionally, it was unable to be delineated whether occurrences of hypotension or bradycardia could have been influenced by administration of concomitant medications.

In conclusion, dexmedetomidine doses greater than $1.5 \mathrm{mcg} /$ $\mathrm{kg} / \mathrm{hr}$ may be as safe as standard doses of 0.2 to $1.5 \mathrm{mcg} / \mathrm{kg} / \mathrm{hr}$; however, no additional benefit in maintaining target sedation level was found. Therefore, if sedation is inadequately controlled or target sedation is unable to be reached with dexmedetomidine at doses greater than $1.5 \mathrm{mcg} / \mathrm{kg} / \mathrm{hr}$, it may be advisable to consider alternative sedative medications in place of dexmedetomidine. 


\section{References}

1 Woods JC, Mion LC, Connor JT, Viray F, Jahan L, et al. (2004) Severe agitation among ventilated medical intensive care unit patients: frequency, characteristics and outcomes. Intensive Care Med 30: 1066-1072.

2 Jaber S, Chanques G, Altairac C, Sebbane M, Vergne C, et al. (2005) A prospective study of agitation in a medical-surgical ICU: incidence, risk factors, and outcomes. Chest 128: 2749-2757.

3 Barr J, Zomorodi K, Bertaccini EJ, Shafer SL, Geller E (2001) A doubleblind, randomized comparison of i.v. lorazepam versus midazolam for sedation of ICU patients via a pharmacologic model. Anesthesiology 95: $286-298$

4 Shafer A (1998) Complications of sedation with midazolam in the intensive care unit and a comparison with other sedative regimens. Crit Care Med 26: 947-956.

5 Barr J, Fraser GL, Puntillo K, Ely EW, Gélinas C, et al. (2013) Clinical practice guidelines for the management of pain, agitation, and delirium in adult patients in the intensive care unit. Crit Care Med 41: 263-306.

6 Precedex $^{\mathrm{TM}}$ [package insert] (2012) Lake Forrest. IL: Hospira.

7 Khan ZP, Ferguson CN, Jones RM (1999) Alpha-2 and imidazoline receptor agonists. Their pharmacology and therapeutic role. Anaesthesia 54: 146-165.

8 Bhana N, Goa KL, Mcclellan KJ (2000) Dexmedetomidine. Drugs 59: 263-268.

9 Pandharipande PP, Pun BT, Herr DL, Maze M, Girard TD, et al. (2007) Effect of sedation with dexmedetomidine vs. lorazepam on acute brain dysfunction in mechanically ventilated patients: the MENDS randomized controlled trial. JAMA 298: 2644-2653.

10 Riker RR, Shehabi Y, Bokesch PM, Ceraso D, Wisemandle W, et al. (2009) Dexmedetomidine vs midazolam for sedation of critically ill patients: a randomized trial. JAMA 301: 489-499.
11 Jakob SM, Ruokonen E, Grounds RM, Sarapohja T, Garratt C, et al. (2012) Dexmedetomidine vs midazolam or propofol for sedation during prolonged mechanical ventilation: Two randomized controlled trials. JAMA 307: 1151-1160.

12 Venn RM, Bryant A, Hall GM, Grounds RM (2001) Effects of dexmedetomidine on adrenocortical function, and the cardiovascular, endocrine and inflammatory responses in post-operative patients needing sedation in the intensive care unit. $\mathrm{Br} J$ Anaesth 86: 650-656.

13 Memiş D, Hekimoglu S, Vatan I, Yandim T, Yüksel M, et al. (2007) Effects of midazolam and dexmedetomidine on inflammatory responses and gastric intramucosal $\mathrm{pH}$ to sepsis, in critically ill patients. Br J Anaesth 98: 550-552.

14 Memiş D, Kargi M, Sut N (2009) Effects of propofol and dexmedetomidine on indocyanine green elimination assessed with LIMON to patients with early septic shock: a pilot study. J Crit Care 24: 603-608.

15 Sessler CN, Gosnell MS, Grap MJ, Brophy GM, O'Neal PV, et al. (2002) The Richmond Agitation-Sedation Scale: validity and reliability in adult intensive care unit patients. Am J Respir Crit Care Med 166: 1338-1344.

16 Jones GM, Murphy CV, Gerlach AT, Goodman EM, Pell LJ, et al. (2011) High-dose dexmedetomidine for sedation in the intensive care unit: an evaluation of clinical efficacy and safety. Ann Pharmacother 45: 740-747.

17 Smithburger PL, Smith RB, Kane-Gill SL, Empey PE (2014) Patient predictors of dexmedetomidine effectiveness for sedation in intensive care units. Am J Crit Care 23: 160-165.

18 Reade MC, O'Sullivan K, Bates S, Goldsmith D, Ainslie WR, et al (2009) Dexmedetomidine vs haloperidol in delirious, agitated, intubated patients: a randomized open-label trial. Crit Care 13: R75.

19 Maldonado JR, Wysong A, van der Starre PJ, Block T, Miller C, et al. (2009) Dexmedetomidine and the reduction of postoperative delirium after cardiac surgery. Psychosomatics 50: 206-217. 